


\section{LA VÍCTIMA DE REgRESO AL SISTEMA DE JUSTICIA PENAL}

JOSÉ LUIS ELOY MORALES BRAND ${ }^{1}$

RESUMEN: El modelo procesal penal acusatorio toma en cuenta a la víctima olvidada en el sistema penal, pues no sólo se trata de un objeto del proceso, sino que cuenta con una serie de facultades y garantías de protección, para solucionar eficaz y rápidamente el conflicto, atendiéndola de inmediato y generando una protección de las autoridades para favorecer a su reparación del daño integral. La víctima cuenta con el derecho a informarse en forma completa de la situación del procedimiento; se incrementan las medidas de protección y aseguramiento de sus derechos; cuenta con una intervención activa con el acusador, y para ejercer la acción de reparación del daño; puede impugnar lo que le perjudique; y en algunos casos se le permite realizar la investigación y continuar con el proceso. La víctima deja de ser un mero objeto de investigación, y se convierte en sujeto procesal interesado y con derechos.

Palabras clave: Derecho Penal, Sistema de fusticia Penal, Garantismo, Victima, Presunción Victimal.

ABSTRACT: The accusatory criminal procedure model takes into account the forgotten victim in the penal system, since it is not only an object of the process, but also has a series of faculties and guarantees of protection, to effectively and quickly solve the conflict, taking care of it immediately and generating a protection from the authorities to favor their repair of the integral damage. The victim has the right to be informed in full of the situation of the procedure; the measures of protection and assurance of their rights are increased; has an active intervention with the accuser, and to exercise the action of repairing the damage; he can challenge what hurts him; and in some cases you are allowed to conduct the investigation and continue with the process. The victim ceases to be a mere object of investigation, and becomes an interested procedural subject with rights.

1 Profesor Investigador y jefe de la Carrera de Derecho de la Universidad Autónoma de Aguascalientes. Miembro del Sistema Nacional de Investigadores. 
Keywords: Criminal Law, Criminal fustice System, Guarantee, Victim, Victim Presumption.

Sumario: I. Preliminares. II. Nueva visión hacia la víctima. III. Garantismo y uso alternativo del derecho. IV. Derechos Humanos, Fundamentales y garantías. V. El Sistema Penal Acusatorio Adversarial. VI. Víctimas y sus derechos en el sistema penal acusatorio. VII. Conclusiones; VIII. Fuentes de investigación.

\section{i. Preliminares}

7 ste trabajo forma parte de los resultados del proyecto de investigación PID16-1 "La víctima y sus derechos en el sistema de justicia penal acusatorio mexicano", que se lleva a cabo en la Universidad Autónoma de Aguascalientes, donde preciso nuevas formas de entender el derecho de las víctimas a tener derechos, como ser un sujeto procesal con participación directa, asesoramiento y control de actuación de autoridades, para lograr una mayor satisfacción de sus necesidades, una reparación integral más adecuada y un verdadero acceso a la justicia.

El Sistema de justicia penal, como mecanismo de control social, opera en el caso de que la conducta exterior del sujeto afecte a otro: la víctima. Este sistema tiene como objetivo la protección de la convivencia de los seres humanos en la comunidad mediante la represión de la criminalidad; sistema que debe sujetarse, invariablemente, al Garantismo Penal de un Estado Constitucional de Derecho, que implica el reconocimiento y respeto de la dignidad humana de todo involucrado en un delito (imputado, víctima, sociedad), provocando un acceso a la justicia con respeto a sus derechos humanos.

En México, anterior a la creación de la Constitución de 1917, el sistema punitivo imperante era inquisitivo que se basaba en la presunción de culpabilidad y, por ende, la prueba de confesión era la más importante, pues obteniéndose, el procedimiento era de mero trámite. A partir de 1917 nuestro sistema penal está basado en el 
principio acusatorio, de la carga probatoria, de contradicción y, en consecuencia, de la presunción de inocencia, pero las leyes secundarias y la práctica penal han contradicho a la Constitución, y los tribunales han emitido criterios respaldando hechos violatorios de esos derechos constitucionales, y regularmente olvidando al afectado del hecho delictivo. De ahí surgieron reclamos para una reforma del sistema de justicia penal, y se genera la reforma Constitucional de 18 de junio de 2008, donde se implementó un Sistema de Justicia Penal Acusatorio en México, con la finalidad de lograr una disminución de las violaciones a derechos humanos en la aplicación de la reacción punitiva, las cuales se dan mayormente en las fases de investigación y ejecución, por parte de autoridades de investigación, acusadores y ejecutores.

El Procedimiento penal acusatorio que se ha estado implementando a partir de esa fecha, tiene por finalidad esclarecer los hechos para determinar si son punibles y declararlos como delito, proteger al inocente del Estado y los particulares, procurar que no se genere impunidad contra el culpable, que los daños causados se reparen, asegurar el acceso a la justicia, mantener el orden jurídico y restablecer la armonía social, en un marco de respeto a los derechos humanos, fundamentales y garantías previstas en la Constitución Política de los Estados Unidos Mexicanos, en el Derecho Internacional de los Derechos Humanos del que el Estado Mexicano sea parte, y toda normatividad que derive de ellos.

A pesar de lo anterior, la situación histórica que prevalece, es de olvido de la víctima, mientras se aseguran los derechos del imputado. Esto se entiende, si se toma en cuenta que, originariamente, en un modelo inquisitivo, la única parte interesada era el Estado, mientras los seres humanos involucrados eran objetos de prueba en el proceso, de ahí que al imputado se le violentaran gravemente sus derechos, mientras la víctima sólo era indispensable como medio de prueba, sin tener derechos que exigir. Se entiende, pero no se justifica, pues uno de los principales fines del nuevo sistema penal 
acusatorio, es la de garantizar la integridad psíquica y física de la víctima, y repararle integralmente el daño que se le ha causado.

La finalidad de este trabajo es compartir esas nuevas visiones de la juridicidad, que influyen en la idea alternativa y garantista de los derechos de las víctimas para lograr su satisfacción, una reparación integral más adecuada y un verdadero acceso a la justicia. Es decir, que la reforma no quede en simple papel, sino que sea realmente aplicada, y ayude a resolver el problema de manera justa, atenuando la reacción del sistema represivo, y ayudando a satisfacer los derechos del afectado por el delito.

\section{Nueva visión hacia la víctima}

Una sociedad se traduce en un conjunto de individuos que se agrupan en un lugar determinado para cumplir fines individuales y colectivos de desarrollo de vida. Por otro lado, el Estado es una organización jurídica de un grupo de personas, bajo un poder de dominación, que se ejerce en determinado territorio.

Entonces, la diferencia entre sociedad y derecho es el poder jurídico que establece su orden y estructura de gobierno o dirección de las voluntades para lograr el bienestar del individuo y la colectividad, lograr su desarrollo y respetar sus derechos humanos y fundamentales. De ahí la existencia de un control social, que deriva del concepto de Estado, como ente organizado para lograr el beneficio social, por lo que es necesario imponer ciertos límites al ejercitar nuestra libertad para evitar conflictos.

Los medios de control social son procesos destinados a inducir conformidad para alcanzar las metas y fines del ser humano; y lo ejercen todos y cada uno de los organismos o instituciones que tienen influencia en la forma de actuar de cada uno de nosotros, como son la familia, escuela, religión, medios de comunicación, instituciones públicas, y un largo etcétera. Cualquiera de los tipos de control social, independientemente de que tiendan a someter la 
conducta del individuo, deben de respetar los derechos humanos y fundamentales de las personas.

Ahora bien, el principal medio de control social formal es el Derecho que busca atenuar las conductas desviadas para lograr la convivencia. Pero no se trata de solo un cuerpo de normas, sino que se vincula con la realidad para proteger valores sociales desde una óptica pluridimensional: el Derecho es todo el conjunto de normas, actitudes, prácticas, costumbres y realidades, que se observan dentro de la interacción humana en un lugar y tiempo determinado, $\mathrm{y}$ se traducen en facultades y obligaciones que buscan lograr, de manera justa, el desarrollo, protección y convivencia de los seres humanos en la sociedad.

¿Por qué hablo de una óptica pluridimensional del Derecho? Retomando el pensamiento de Jesús Antonio de la Torre Rangel, ${ }^{2}$ el Derecho no es un concepto unívoco, no sólo se traduce en ley, sino que la juridicidad viene antes para resolver necesidades; su raíz es el ser humano, que exige lo que es suyo, pero además, regula el deber de la conducta hacia otro, que ha sido negado y excluido, pero está dentro de la estructura social; y dentro de esa confrontación, dentro de esa analogía, coincido en que la materia jurídica no sólo se reduce a la formulación y existencia de leyes a las cuales la persona sujeta su actuar; ya que el derecho, es más que pura legislación: contiene un valor que es la justicia, y la cual se alcanza cuando la aplicación de la norma es eficaz, pues resuelve, o por lo menos aminora, el problema social para la cual fue creada.

Siguiendo a Oscar Correas $^{3}$ el Derecho es un discurso de carácter prescriptivo, producido por quien detenta el poder, que es reconocido como legítimo por la mayor parte de una sociedad, y organiza la violencia, que se legitima por reconocer ese discurso como

2 Jesús Antonio De la Torre Rangel, Iusnaturalismo, Personalismo y Filosofía de la Liberación. Una visión integradora, Sevilla, Mad, 2005, pp. 54 y 55.

3 Oscar Correas, Introducción a la sociología jurídica, México, Distribuciones Fontamara, 2000, p. 22. 
orden establecido. Por ello, el derecho debe provocar un cambio social para la satisfacción de las necesidades humanas; y ayudar al individuo en sociedad a desarrollarse en convivencia justa, ejercer sus derechos y respetar a los demás. Esta visión es de la norma con la realidad.

Pero además, el orden jurídico tiene como punto de partida los Derechos Humanos, y estos a su vez, la esencia humana; ${ }^{4}$ por lo que la filosofía y el derecho están íntimamente relacionados pues buscan un cambio social de fondo en el ser humano, donde la juridicidad se encuentre a su servicio y respete sus derechos.

Tratan de convertirse en un arma ideológica de los grupos desfavorecidos, para auxiliarlos en su liberación de aquellos que detentan el poder sólo para imponer sus intereses. También verifican lo justo o injusto en la realidad concreta de solución a los problemas sociales; de ahí que ayuda a determinar si una sociedad es opresora, por no existir justicia y bien común, o si es liberadora y respetuosa de esos valores. ${ }^{5}$ La Filosofía en su relación con la Sociología Jurídica busca que el Derecho otorgue al hombre lo necesario para su desarrollo integral; es decir, que se le trate como sujeto, y no como un simple objeto de quien aplica la norma.

La Filosofía es necesaria ya que el Derecho se ha estancado en lo que debe ser, sin importarle lo que debe ser en la realidad. El riesgo que se corre con el análisis Filosófico es que no siempre provoca neutralidad total dentro de la Sociología Jurídica y puede llegar al subjetivismo, ${ }^{6}$ pues en los estudios sociales influyen los motivos, intereses, formación, ideología y forma de pensar del autor, así como el medio en que se desenvuelve.

De ahí que cualquier estudio o análisis del derecho debe tener una visión pluridimensional; es decir, no sólo debe enfocarse a la

4 Jesús Antonio De la Torre Rangel, Sociología jurídica y uso alternativo del derecho, Aguascalientes, ICA, 1997, p. 19.

5 Idem, p. 31.

6 Idem, p. 42. 
norma o a las leyes, sino que debe observarse que tiene un contenido de valor, norma, y hechos; por lo que cualquier estudio jurídico que no aborde estos tres niveles, tiene una visión recortada de lo que es el derecho. ${ }^{7}$

Por ejemplo, el discurso del Derecho Penal se traduce en la defensa de las libertades, pues sólo interviene después de que se exteriorice una conducta dañosa, puesto que, al cometerse un hecho delictivo, la norma penal presupone que el autor entendía qué conducta debía realizar, pero se percata de que no fue realizada, por lo que debe atender el problema, y logar una solución justa, alternativa y humana para los derechos de la víctima, del imputado y la sociedad.

El problema lo encontramos cuando la realidad se disimula por medio del discurso del Derecho y su lenguaje, como en el caso de la igualdad formal de los individuos para la aplicación de la ley, lo cual puede permitir superar las adversidades en un momento dado; pero si se institucionaliza ese proceder, conduce a la dictadura de la mentira ejercida desde el poder. ${ }^{8}$ Y esto es lo que ha pasado con la víctima, pues si bien se le reconoce un trato igualitario en facultades, derechos y oportunidades, sigue siendo empleada como medio de prueba, y su participación quiere ser reducida simplemente a buscar un pago en efectivo que compense su afectación.

Con base en lo anterior, para determinar el papel de la víctima en el proceso penal acusatorio, debemos atender a esta pluridimensión, pues el sistema de justicia penal mexicano se conforma de las normas y sus instancias de aplicación en la realidad, que requiere de una valoración sociológica, sistémica y justa del afectado, el agresor y la comunidad. Por ello, esta visión, siguiendo a Fernando

7 Martín Laclau, Conducta, norma y valor; ideas para una nueva comprensión del derecho, Buenos Aires, Abeledo Perrot, 1999, p. 71.

8 Alex Grijelmo, La seducción de las palabras; un recorrido por las manipulaciones del pensamiento, Madrid, Santillana, 2004, p. 217. 
Rojas Hurtado, ${ }^{9}$ debe promover e introducir cambios sociales, con una nueva idea de justicia, que implica el reemplazo de todo o parte del sistema legal inquisitivo que olvidaba a las víctimas, por otro basado en la empatía y solidaridad con los involucrados en el hecho delictivo, tomando en cuenta sus diferencias y particulares necesidades; y además buscar cambios fundamentales en el pensamiento de las autoridades que operan y ejecutan el sistema, para lograr la efectividad en la resolución del conflicto y la satisfacción de necesidades derivadas del hecho delictivo.

Entonces, el Derecho no es sólo dogmática, a pesar de que en ocasiones se siga sosteniendo así, ya que las normas deben aplicarse en relación con el contexto, los antecedentes, y la realidad social, atendiendo a su finalidad de justicia, que no es más que la satisfacción adecuada de las necesidades, y la resolución del conflicto en una colectividad.

\section{ili. Garantismo y uso alternativo del Derecho}

Esta investigación no puede dejar a un lado una reflexión sobre las coincidencias entre el garantismo y el uso alternativo del derecho, como base de la satisfacción de derechos humanos y fundamentales. Según el italiano Luigi Ferrajoli, garantía es una expresión del léxico jurídico con la que se designa cualquier técnica normativa de tutela de un derecho subjetivo; el Garantismo será entonces la tutela de aquellos valores o derechos fundamentales cuya satisfacción, aún contra los intereses de la mayoría, es el fin justificador del derecho; ${ }^{10}$ desde aquí observamos a que si bien se establece como necesaria una norma que garantice un derecho fundamental, también se precisa que éstos deben satisfacerse a toda costa, lo que

9 Jesús Antonio De la Torre Rangel, Sociología jurídica..., op. cit, p. 11.

10 Luigi Ferrajoli, Derecho y razón; teoría del garantismo penal, Madrid, Trotta, 2011, p. 336. 
implica una búsqueda valorativa y fáctica en la resolución de problemas sociales.

Por otro lado, el "Gramscismo" es una corriente neo marxista desarrollada por el también italiano Antonio Gramsci, donde precisa que el Estado es todo el complejo de actividades prácticas y teóricas, con las cuales la clase dirigente no sólo justifica y mantiene su dominio, sino también logra obtener el consenso activo de los gobernados, por lo que el derecho es simple instrumento de poder que educa a la nueva civilización, y debe dejar de aplicarse de esa forma, pues no resuelve los problemas sociales eficazmente, sino que mantiene un control y conformismo hacia la clase hegemónica.

Tomando estas ideas de Gramsci, la corriente del uso alternativo del derecho plantea la posibilidad del uso de la juridicidad vigente por los pobres y en su propio servicio; pobre como categoría sociológica de grupos humanos que vienen a constituirse en sujetos usuarios de la juridicidad alternativa, es decir aquellos que tienen hambre y falta de justicia y derechos; sufren de desigualdad y opresión; difieren de la clase social que se define por categoría económica; no cuentan con determinados derechos frente a otros grupos sociales y son grupos solidarios frente a la clase dominante. ${ }^{11}$

El uso alternativo del derecho ${ }^{12}$ es una corriente doctrinal y de praxis jurídico política, generalmente de inspiración marxista, que sostiene la naturaleza política del derecho, su carácter de clase y admite la posibilidad de su interpretación contra los intereses de la clase dominante y al servicio de las clases oprimidas; es una práctica jurídico política en el sentido de utilización de las normas jurídicas como objetos, intereses y valores distintos de los que reivindica la clase burguesa dominante y hegemónica, en la creación y aplicación del derecho. Se traduce en diversas acciones encaminadas a que toda la juridicidad, normatividad, derechos subjetivos, ideas y

\footnotetext{
11 Jesús Antonio De La Torre Rangel, Sociología jurídica..., op. cit, p. 37.

12 Idem, 79 y 80.
} 
concretizaciones de justicia sea usada al servicio de los pobres como sujeto histórico tanto a ante las instancias judiciales y administrativas del estado, como entre ellos mismos, creando y recreando la solidaridad.

Ahora bien, el uso alternativo del derecho no es una ideología que debe aplicarse a capricho del ser humano, es necesaria una búsqueda en el ordenamiento jurídico en vigor, aquello que sirve para los propósitos de realizar la justicia; es decir debemos buscar la solución justa y luego arroparla de legalidad, ${ }^{13}$ ya que el derecho es un ente artificial que se produce en la realidad social y debe defenderse delante del Juez; deben evidenciarse las contradicciones entre la ley y la realidad, para así reforzar que el derecho no es pura norma, sino también valor y realidad; y tener siempre la conciencia de que la legalidad es producida y sirve al ser humano, pues es un producto cultural que debe adecuarse a la realidad, y no le hombre a un ente artificial.

Con estas breves ideas nos damos cuenta que la corriente garantista no busca todas las soluciones en la norma, pues Ferrajoli precisa que los derechos fundamentales deben ser protegidos aún en contra de los intereses de la mayoría, es decir la de proteger al más débil frente al más fuerte; lo cual propuso Antonio Gramsci al establecer que el derecho debe servir a la totalidad en contra de los intereses de la clase burguesa, tomándose en cuenta que la juridicidad no es sólo la norma, sino también los valores que tienen los pueblos y los hechos concretos en los que se desenvuelven día a día, y en los cuales claman justicia, traducida en la satisfacción de las obligaciones y deberes mínimas que deben observarse para vivir dignamente. Así, observamos que el garantismo de Ferrajoli, no deja a un lado el contenido valorativo que da origen a esos derechos sustantivos, pues el ser humano es el que crea el derecho, y no el derecho a la persona.

13 Idem, p. 91. 
Antonio Gramsci invierte la relación marxista entre estructura y superestructura, pues da primacía a lo espiritual sobre lo económico y quiere que minoría (burgueses) y muchedumbre (pobres) profesen la misma religión. Expone que para llegar a una sociedad totalitaria es necesaria una revolución, pero no armada, sino intelectual y moral, mediante los intelectuales orgánicos que harán una guerra de posiciones, asaltando los núcleos de influencia ideológica y cultural, de manera que el poder político caiga en manos del partido que se mantendrá en el poder, no por la fuerza, sino por el consenso, ya que existirá identidad cultural y moral; una unidad ideológica entre gobernantes y gobernados, que formarán una totalidad espiritual o comunión de lo justo. Luigi Ferrajoli perteneció al grupo de la Magistratura Democrática, que era conformado por jueces alternativistas italianos; pero al parecer se alejó del alternativismo y desarrolla el garantismo, por el eminente rechazo social al marxismo, pero además como una estrategia política académica, con el fin de exponer sus ideas libremente en las universidades. ${ }^{14}$

Pero sus ideas siguieron influenciadas por ese pensamiento, pues Ferrajoli precisa que existe una divergencia entre la normatividad del modelo en nivel constitucional y su ausencia de efectividad en los niveles inferiores, lo que implica el riesgo de hacer de los principios constitucionales una simple fachada que se traduce a meras funciones ideológicas; ${ }^{15}$ así una Constitución puede ser avanzadísima por sus principios y derechos y no pasar de ser un pedazo de papel si carece de garantías que permitan el control y neutralización del poder y derecho ilegítimo; de ahí que el Garantismo sea una teoría de la divergencia entre normatividad y realidad. ${ }^{16}$ Encontramos así la primera evidencia del uso alternativo del derecho, pues se afirma que existen contradicciones entre la norma y su efectividad, con lo

14 Jesús Antonio de la Torre Rangel, Cátedra de Sociología furídica, Maestría en Derecho de la Universidad Autónoma de Aguascalientes, 12 de abril de 2003.

15 Luigi Ferrajoli, Derecho y razón..., op. cit., p. 851.

16 Idem, p. 852. 
que se evidencia que el derecho no es sólo ley, sino también valor y realidad; inclusive el propio Ferrajoli precisa que su teoría del Garantismo debe estudiarse en los planos de relación entre derecho y valores ético políticos externos, el jurídico y relaciones entre constitución y leyes ordinarias y su aplicación, y sociológico o relación del derecho y prácticas efectivas. ${ }^{17}$

Precisa además que son derechos fundamentales todos aquellos derechos subjetivos que corresponden universalmente a todos los seres humanos en cuanto dotados del status de personas, de ciudadanos o personas con capacidad de obrar; entendiendo por derecho subjetivo cualquier expectativa positiva (de prestaciones) o negativa (de no sufrir lesiones) adscrita a un sujeto por una norma jurídi$\mathrm{ca}^{18}{ }^{18}$ es decir, recurre a la parte valorativa ya que la naturaleza jurisprudencial y doctrinal del derecho válido que se relaciona con el derecho natural o la justicia se resuelve en total incertidumbre y arbitrariedad del derecho vigente, pues los juicios de validez o invalidez de la norma pueden ser más o menos opinables, como se ve en leyes válidas que han sido declaradas inválidas. ${ }^{19}$

Según el garantismo los derechos fundamentales no son negociables y corresponden a todos en igual medida; a diferencia de las situaciones jurídicas de poder que se encuentran sujetas a transmisiones, investidura y extinciones, las libertades y los derechos sociales no se intercambian ni se acumulan, sino que permanecen siempre iguales así mismos para cada persona, sin que jamás sufran interferencias por la variación de las situaciones jurídicas; la falta o su injusta privación en perjuicio de cualquier persona viola el valor de todas las personas; ${ }^{20}$ Ferrajoli afirma también que éstos dere-

17 Idem, p. 855.

18 Luigi Ferrajoli, Derechos y garantías; la ley del más débil, Madrid, Trotta, 1999, p. 37.

19 Luigi Ferrajoli, Derecho y razón... op. cit., pp. 869 y 875.

20 Idem, p. 911. 
chos subjetivos son atribuidos al sujeto por una norma jurídica, ${ }^{21}$ aunque existan antes que la ley, pues si la satisfacción de los valores fundamentales o intereses naturales es la razón de ser de las cosas artificiales llamadas instituciones jurídicas y políticas, ${ }^{22}$ no puede concebirse que el derecho fundamental sólo pueda ser exigido por la persona hasta en tanto no sea reconocido por la norma; así, vemos unificación con el pensamiento Gramscista, en el sentido de que las leyes deben ser precedidas por la costumbre, pero esto realmente no sucede con el derecho pues siempre ha luchado para afirmarse y crear una nueva costumbre; en este sentido, se supone que el derecho es una expresión integral de toda la sociedad, lo cual es falso, pues sólo expresa la clase dirigente que impone a toda la sociedad aquellas normas de conducta que están más ligadas a su razón de ser y a su desarrollo; entonces, la función máxima del derecho es la de presuponer que todos los ciudadanos deben aceptar libremente el conformismo señalado por el derecho, en cuanto que todos pueden convertirse en elementos de la clase dirigente, ${ }^{23}$ la cual decidirá, con base a su poder, cuales son los derechos fundamentales que le conviene proteger, de acuerdo a sus intereses. Ferrajoli menciona que la lesión de los derechos fundamentales por parte del estado justifica no simplemente la crítica o el disenso sino la resistencia a la opresión hasta la guerra civil, ${ }^{24}$ por lo que el Estado muchas veces sólo protege los valores que le interesan para obtener el consenso y mantener el poder.

Es aquí donde se refleja la unión entre el Gramscismo y Garantismo, pues se acepta el uso alternativo del derecho en beneficio de la justicia, ya que los argumentos no se dirigen sólo a la norma, sino a sus aspectos de falta de efectividad e invalidez, donde encontraremos entonces el trabajo del juez y del jurista, en oposición a la

21 Luigi Ferrajoli, Derechos y garantías..., op. cit., p. 59.

22 Luigi Ferrajoli, Derecho y razón..., op. cit., p. 854.

23 Antonio Gramsci, Cuadernos de la Cárcel, México, Era, 1999, p. 83.

24 Luigi Ferrajoli, Derecho y razón..., op. cit., p. 859. 
total fidelidad a la ley y simple descripción y no valoración del derecho positivo vigente. ${ }^{25}$ Entonces el Estado es todo el complejo de actividades prácticas y teóricas, con las cuales la clase dirigente no sólo justifica y mantiene su dominio, sino también logra obtener el consenso activo de los gobernados; el Derecho es un orden político y legal, expresión programática educativa de quién y porqué lo infringe; es utilizado como obstaculizador de las fuerzas de la historia pues no conduce al pueblo a la evolución, ${ }^{26}$ sino a su sometimiento a un nuevo tipo de civilización; es decir a creer una realidad que es construida socialmente.

El punto de vista externo del garantismo es el de las personas, por lo que la tolerancia consiste en el respeto de toda las posibles identidades personales y de todos los correspondientes puntos de vista; así, la igualdad reside en el valor asociado de manera indiferenciada a todas las personas; es el igual valor asignado a todas las diferentes identidades que hacen de cada persona un individuo diferente a los demás y de cada individuo una persona como todas las demás. ${ }^{27}$ La Igualdad quiere decir entonces, que los diferentes deben ser respetados y tratados como iguales, pues de hecho, en las personas hay diferencias que son aquellas que deben ser tuteladas en respeto a la identidad de la persona. ${ }^{28}$ Con la igualdad formal se conviene que los hombres se consideren iguales; con la igualdad sustancial se conviene que los hombres deben ser tratados tan iguales como sea posible sin prescindir del hecho que son social y económicamente desiguales (respetarlos y compensarlos); así pues, las garantías de los derechos de libertad aseguran la igualdad formal (derechos a la diferencia), y las garantías de los derechos sociales posibilitan la igualdad sustancial (derechos a la compensación

25 Idem, p. 872.

26 Jesús Antonio De la Torre Rangel, Cátedra de Sociología Jurídica, Maestría en Derecho de la Universidad Autónoma de Aguascalientes, 12 de abril de 2003.

27 Luigi Ferrajoli, Derecho y razón..., op. cit., p. 906.

28 Luigi Ferrajoli, Derechos y garantías..., op. cit., p. 79. 
de desigualdades); ${ }^{29}$ es entonces donde Garantismo y Gramscismo nuevamente se reencuentran, pues con el nacimiento y desarrollo de las desigualdades, aparece el carácter obligatorio del derecho, que aumenta con la sola finalidad de resolver un problema social de manera justa.

Y si esto no fuera suficiente, basta la afirmación en el sentido de que puesto que los jueces tienen el poder de interpretar las leyes y de suspender su aplicación si las consideran inválidas por contrastar con la Constitución, no se puede decir, en rigor, que tengan la obligación jurídica de aplicarlas; ya que si bien para que una norma exista o esté en vigor basta con que cumpla con las condiciones procesales del acto normativo, para que sea válida debe satisfacer su sustancia, es decir el respeto a los valores constitucionales cuya lesión produce un conflicto entre normas de significado distinto. ${ }^{30}$

\section{Derechos humanos, fundamentales y garantías}

Teniendo como base esa visión pluridimensional de la juridicidad, y la clara relación entre el garantismo y el uso alternativo del derecho, que busca la satisfacción de las necesidades humanas, antes de exponer lo que es el sistema de justicia penal, y el papel que tiene la víctima en su interior, es necesario precisar lo que entendemos por derechos humanos, su reconocimiento interno y los mecanismos para lograr su efectividad.

En un Estado Constitucional de Derecho, las autoridades y los seres humanos quedan sometidos a la Constitución o Ley Fundamental, en la cual se establece la forma de organización del Estado, la realización de sus funciones, pero sobre todo la protección y garantía de los derechos humanos, reconocidos como fundamentales, a través de la precisión de los límites impuestos a las autoridades,

\footnotetext{
29 Luigi Ferrajoli, Derecho y razón..,. op. cit., p. 907.

зо Idem, pp. 873 у 874.
} 
para hacer efectivo el goce de esos derechos. Así, el control social de un Estado Constitucional de Derecho tiene un fin principal: proteger los Derechos Humanos y Fundamentales de los seres humanos.

Los Derechos Humanos son un concepto político, pues se tratan de criterios de legitimidad política, en la medida que se protejan, y representan una visión moral particular de una sociedad y su realidad. ${ }^{31}$ Para establecer qué son los Derechos Humanos, y qué es lo que debe proteger el Estado, retomaré el concepto desarrollado por los catedráticos de la Universidad de Alcalá de Henares. Para ellos, ${ }^{32}$ los Derechos Humanos son demandas de abstención o actuación, derivadas de la dignidad de la persona y reconocidas como legítimas por la comunidad internacional, siendo por ello merecedoras de protección jurídica por el Estado.

Ahora bien, la relación de los Derechos Humanos con los Derechos Fundamentales existe, ya que más que buscar un concepto de Derechos Humanos, tenemos que verificar que en la realidad se otorga al hombre lo necesario para su desarrollo integral; es decir, que se le trate como sujeto, y no como un simple objeto de quien aplica la norma. Pero, ¿qué son los Derechos Fundamentales?

Los Derechos Fundamentales son los componentes estructurales básicos del orden jurídico, en razón de que son la expresión jurídica de un sistema de valores que, por decisión del constituyente, ha de informar el conjunto de la organización jurídica y política. En consecuencia, de la obligación de sometimiento de todos los poderes a la Constitución no solamente se deduce la obligación negativa del Estado de no lesionar la esfera individual o institucional protegida por los Derechos Fundamentales, sino también la obligación positiva de contribuir a su efectividad y de los valores que represen-

31 Jack Donnelly, Derechos humanos universales, México, Gernika, 1998, p. 31.

32 Ricardo García Manrique y Guillermo Escobar Roca, Guillermo, cátedra Estado de Derecho y Derechos Humanos, Programa de Apoyo a Defensores de Derechos Humanos en Iberoamérica, de la Federación Iberoamericana del Ombudsman, Alcalá de Henares, Madrid, 2007. 
tan, aun cuando no exista una pretensión subjetiva por parte del ciudadano. ${ }^{33}$

Siguiendo la misma idea de los catedráticos de la Universidad de Alcalá de Henares, los Derechos Fundamentales son los más importantes en un Estado Constitucional de Derecho, y en consecuencia son los pilares básicos del ejercicio adecuado de la Política Criminal, en virtud de que su mera incorporación a una Constitución implica que gozan del mayor nivel de garantía o protección, vinculan a las autoridades y organismos del Estado para su aplicación directa al tomar decisiones, y sólo pueden limitarse por motivos serios y racionales.

Los Derechos Humanos influyen dentro de la Constitución y los Derechos Fundamentales, al determinar el catálogo de esos derechos, ampliando su reconocimiento con base al derecho internacional de los derechos humanos, interpretando su contenido con base al principio pro homine o a favor del ser humano, buscando siempre la aplicación del derecho positivo para satisfacer las necesidades humanas.

Ahora bien, conociendo que los derechos humanos son demandas de satisfacción de necesidades que de entrada se protegen a través del establecimiento de valores básicos a nivel constitucional como máximo nivel de protección, es necesario aclarar que ningún derecho es absoluto, salvo la dignidad humana que debe respetarse y tomarse en cuenta en todo momento al tomar decisiones sobre la afectación de un derecho. En este sentido, como igual lo indican los catedráticos de la Universidad de Alcalá, ${ }^{34}$ los derechos pueden ser intervenidos mediante conductas ejecutadas por particulares o

\footnotetext{
33 Tribunal Constitucional Español, sentencia 53/1985, del 11 de abril de 1985.

34 Ricardo García Manrique y Guillermo Escobar Roca, Guillermo, cátedra Estado de Derecho y Derechos Humanos, Programa de Apoyo a Defensores de Derechos Humanos en Iberoamérica, de la Federación Iberoamericana del Ombudsman, Alcalá de Henares, Madrid, 2007.
} 
entidades públicas, que afectan negativa y significativamente a una o más de las inmunidades o facultades que integran su contenido.

Esto significa que los derechos pueden ser restringidos o afectados cuando el propio sistema lo permita, por lo que debemos saber cuándo la intervención o restricción del derecho es válida y legítima. Primeramente, los derechos se encuentran limitados por el respeto a los derechos de los demás; es decir, los derechos se limitan cuando el hombre deja de ser social, lo que implica que conscientemente agrede o afecta los derechos de los demás sin estar autorizado para hacerlo.

Si los derechos fundamentales gozan, por definición, de rango constitucional, sólo en normas del mismo rango podrá encontrarse la justificación de sus afectaciones, y su intervención debe seguir las siguientes reglas que integran el principio de proporcionalidad: ${ }^{35}$

a) Adecuación o idoneidad: La intervención debe estar establecida en la norma constitucional, por ser adecuada para resolver un conflicto en la sociedad;

b) Necesidad o indispensabilidad: Cuando existan dos o más medios, todos ellos constitucionalmente legítimos, para la consecución del fin que justifica la intervención, deberá optarse por el menos dañoso para el derecho intervenido; y

c) Ponderación o proporcionalidad en sentido estricto: Cuando entran en conflicto los derechos de las personas, debe intentarse, en la medida de lo posible, una ponderación o equilibrio entre ambas, procurándose el respeto esencial de los intereses enfrentados (lo cual puede llegar a ser un ejercicio subjetivo atribuir mayor o menor peso a cada uno de los intereses en conflicto).

Siguiendo esta idea sobre las intervenciones, las Garantías son mecanismos jurídicos específicos de protección de un derecho fun-

35 Idem. 
damental y humano, o las técnicas para no restringir indebidamente el goce de un derecho. Se traducen en las obligaciones o prohibiciones relativas a restringir de manera indebida el goce del derecho y con ello verificar la legitimidad de la intervención.

En un Estado Constitucional de Derecho, la garantía fundamental de los derechos humanos y fundamentales es la Jurisdicción, los tribunales judiciales, ya que la función judicial es una garantía de todos los seres humanos frente al mismo Estado, al estar dirigido a impedir arbitrariedades y abusos potestativos sobre sus derechos, así como obligar a la autoridad a satisfacerlos.

$\mathrm{Al}$ existir varios sistemas o mecanismos que pretenden reaccionar contra las desviaciones sociales, y algunos se insertan en la estructura del Estado, consecuentemente, será la forma o clase de Estado la que condicione las prácticas de control social; ${ }^{36}$ y en un Estado Constitucional de Derecho, esos mecanismos se ven sustentados en la protección de los Derechos Fundamentales de las personas a las que va dirigido, al someterse a normas de actuación diseñadas para asegurar la objetividad de la intervención y el respeto de los individuos involucrados en el conflicto. ${ }^{37}$

En consecuencia, una verdadera política criminal democrática que tenga como límites los Derechos Humanos y Fundamentales de las personas, será aquella que construya un mecanismo de control social penal que tienda a la protección de los seres humanos, afectándolos lo menos posible. Esta visión influye en el Derecho Penal, para desarrollar el principio de intervención mínima o última ratio de la reacción penal: frente a un conflicto social, el Estado Constitucional de Derecho debe, antes que nada, desarrollar una política social que conduzca a su prevención o solución o, en último término, pero sólo en último término, optar por definirlo y sancionarlo

36 Santiago Mir Puig, Nuevas tendencias en política criminal-Una auditoría al Código Penal español de 1995 -, s. cd., B de F, 2006, p. 116.

37 Antonio García-Pablos de Molina, Tratado de criminología, Valencia, Tirant lo Blanch, 2003, pp. 197 y 198. 
como criminal. Cuando así lo hace está ejercitando entre diferentes alternativas que puedan presentarse para la solución del conflicto una opción política, que en forma específica tomará el nombre de política criminal en tanto que está referida a la criminalización del conflicto. $^{38}$

\section{v. El Sistema Penal Acusatorio Adversarial}

La finalidad esencial del Estado Constitucional de Derecho es lograr el desarrollo, protección y convivencia de los seres humanos; y uno de los mecanismos para lograrlo es el Sistema de Justicia Penal, que se trata de un control social punitivo o represivo, a cargo del Estado, que es la respuesta más violenta en contra de los ciudadanos que rompan el orden de la comunidad. Y en virtud de que este medio de control social es una estructura de poder del Estado, debe estar sometido y regulado al Derecho, limitado claramente para controlar su ejercicio, de tal forma que sus detentadores no abusen de él en su relación con los otros integrantes del conjunto social. ${ }^{39}$

El conflicto para limitarlo es que el derecho punitivo ha tenido tantas justificaciones como modelos políticos han existido; así en cada modelo político se produce un Derecho Penal que se requiere para cumplir con los fines estatales; entonces la función del Derecho Penal y su legitimación depende de la función que se atribuya al Estado específico que promulgue la legislación; ${ }^{40}$ pero en un Estado Constitucional de Derecho las prácticas de control social deben estar sustentadas en la protección de los derechos fundamentales de las personas a las que va dirigido.

38 Juan Bustos, Lecciones de Derecho Penal, Madrid, Trotta, Madrid, 1997, p. 29.

39 Oscar Emilio Saurre, La crisis de legitimidad del sistema jurídico penal, s. cd., Editorial Universidad, 1998, p. 75.

40 Serafin Ortiz, Los fines de la pena, México, Instituto de Capacitación de la PGR, 1993, p. 64. 
Y es aquí donde hablaremos del Sistema Penal Acusatorio Adversarial, como un mecanismo procesal penal, que pretender responder al problema de la criminalidad, mediante el respeto de los derechos de los ciudadanos.

La finalidad del Sistema de Justicia Penal es la de investigar un hecho y verificar si el mismo constituye o no un delito, pero ello no implica que puedan emplearse cualquier tipo de medios para obtener, a toda costa, el conocimiento de esa realidad. ${ }^{41}$ Cualquier Sistema de Justicia Penal, legalmente instituido, se enfrenta a la necesidad de armonizar, por un lado, el interés en la búsqueda de la verdad y, por otro, el interés del procesado en la salvaguarda de sus derechos individuales. ${ }^{42}$ En consecuencia el procedimiento penal no tiene que renunciar a la búsqueda de esa verdad, sino que solamente tiene que atemperar esa meta a las limitaciones que se derivan de los derechos fundamentales reconocidos en la Constitución ${ }^{43}$ y demás normas de la materia. La verdad, en una sentencia penal, debe verse como una realidad consensuada por los medios de convicción aportados al juzgador. ${ }^{44} \mathrm{Al}$ reconocer a las personas como posibles sujetos del sistema penal, que tienen intereses que se contraponen a la pretensión punitiva, nos lleva a hablar de una verdad real, limitada por los derechos fundamentales. En el modelo garantista se invierte la idea de que el fin de la verdad justifica cualquier medio, de modo que es únicamente la naturaleza del medio, lo que garantiza la obtención del fin. ${ }^{45}$

41 Karl Gössel, El proceso penal ante el Estado de Derecho, Perú, Editora Jurídica Grijley, 2004, p. 64.

42 Claus Roxin, La evolución de la política criminal, el derecho penal y el proceso penal, España, Tirant lo Blanch, 2000, p. 121.

43 Francisco Muñoz Conde, Búsqueda de la verdad en el proceso penal, Buenos Aires, Hammurabi, 2000, p. 97.

44 Karl Gössel, op. cit., p. 190.

45 Luigi Ferrajoli, Derecho y razón..., op. cit., p. 608. 
Así, encontramos que la función represiva se ha dado bajo distintas perspectivas que originaron a los sistemas punitivos denominados como acusatorio, inquisitivo y mixto. Los griegos y romanos establecen un sistema de acusación, donde el afectado debe acusar al agresor frente a una autoridad, quien decidirá quién tiene la razón, con base a las pruebas que las partes le exhiban oralmente, respetando ante todo la igualdad de los involucrados. En estos procedimientos, regularmente se pedía una caución al acusador para indemnizar al acusado en caso de una acusación falsa o que no alcanzara los votos del tribunal. ${ }^{46}$

Pero los sistemas monárquicos basados en el poder divino, y con la finalidad de controlar todos los sectores de la sociedad, ${ }^{47}$ provocan que el poder social organizado imparta justicia a nombre de la divinidad y del interés público, donde el afectado denunciaba al agresor ante el tribunal, quien investigaba, decidía, imponía y ejecutaba las penas, dándose origen al sistema inquisitivo.

En este modelo inquisitivo, el presunto autor de un hecho antisocial sufre múltiples vejaciones y violaciones a sus derechos como persona; sus garantías para defenderse eran nulas, ya que se le aislaba e incomunicaba, incluso algunas veces ni siquiera sabía el por qué era juzgado, y quién le imponía el castigo; el Estado comprende que la investigación de los delitos es una función social de gran importancia que debe ser de su incumbencia, pero se cae en el error de darle la facultad persecutoria al Juez, quien se encargaba de averiguar los delitos, buscar las pruebas, y resolver los negocios que ellos mismos investigaban, para convertirse en Juez y parte dentro de un sistema inquisitivo de enjuiciamiento. La participación del acusador se traducía en una entidad decorativa que se cruzaba de brazos para que el Juzgador practicara las diligencias y estar pendiente de tales actos.

46 Lorena Bachmaier, Proceso penal y sistemas acusatorios, Madrid, Marcial Pons, 2008, pp. 50 y 51 .

47 Ibidem, pp. 57 y 58. 
En síntesis, un sistema inquisitivo establece un procedimiento escrito y secreto; no existe posibilidad de defensa para el autor del hecho; la base del procedimiento es la confesión del hecho y el pecado, por lo que las herramientas más efectivas son el aislamiento, la incomunicación y la tortura; el autor no conocía la acusación; no había igualdad del partes pues los Jueces, que nunca eran vistos, se encargaban de investigar, acusar, procesar, valorar, juzgar, imponer y ejecutar las sanciones. Se traduce en un modelo en el que el juicio es una careta necesaria para imponer una pena, con base a la dinámica de "el fin justifica los medios", pues se permite detener y consignar sin averiguar, en vez de averiguar para consignar y, como última opción, detener, y que la declaración del imputado sea un medio de defensa. Inclusive, la propia autoridad tiene facultades "amplias" para recabar pruebas "en razón de la verdad", perdiendo la imparcialidad.

Por otro lado, un sistema acusatorio requiere la legitimidad de los medios para llegar al fin, por lo que los derechos humanos y fundamentales son la base de la actuación de las autoridades, en un modelo en el que existe un órgano público encargado de la acusación, distinto a quien Juzga, donde existe igualdad para los sujetos procesales dentro de un juicio público y oral, ante un juez imparcial e independiente, en donde existe la defensa adecuada y la participación del afectado en una forma real. Es decir, un modelo en el que se requiere juicio, con garantías procesales, para imponer pena. ${ }^{48}$ Finalmente, un modelo adversarial es aquel donde el acusador y el acusado se consideran adversarios o partes en conflicto, el cual deberá ser resuelto en el procedimiento penal en función al dinamismo que impregnen a sus actividades: producir la prueba, fortalecer su teoría del caso y debilitar la de su contraparte, y negociar la solución del conflicto. ${ }^{49}$

48 Luigi Ferrajoli, Derecho y razón..., op. cit., p. 605.

49 Juan Pastrana, Implementación del proceso penal acusatorio adversarial en Latinoamérica, México, Flores Editor y Distribuidor, 2009, p. 18. 
Actualmente, no existe procedimiento que sea radicalmente oral o escrito, por lo que se catalogan de acuerdo a lo que predomine en sus actuaciones, pero un Sistema Acusatorio Adversarial se caracteriza en que las partes acuden ante el tribunal y someten a su consideración una causa, para que éste pueda dictar resolución; por lo que carecería de lógica convocar a las partes ante el Juez para formular lo que convenga a su derecho, si, de otro modo, sus alegaciones hubieran de presentarse por escrito. Por ello, la oralidad va ligada a la inmediación, es decir, a la necesidad de que lo actuado por los sujetos procesales en el juicio contradictorio, se realice ante la presencia del juzgador. ${ }^{50}$

Un Sistema Acusatorio Adversarial no es simplemente un procedimiento rápido mediante una audiencia verbal; un verdadero Sistema Acusatorio implica mantener un control jurisdiccional de todas las fases del Sistema de Justicia Penal, desde el inicio de la investigación, hasta la ejecución final de las sanciones, lo que, bien aplicado, disminuye las violaciones a derechos humanos que mayormente se dan en las fases de investigación del hecho y ejecución de las penas.

En síntesis, la propuesta del Sistema Penal Acusatorio Oral en México, es la siguiente:

1. La autoridad está obligada a implementar medidas alternativas que no impliquen necesariamente un procedimiento judicial para la imposición de una sanción, para buscar lograr la reparación del daño integral a la víctima, que el imputado tome conciencia de su acción, se reintegre a la sociedad, no se contamine en reclusión, y se depuren las acciones procesales, para que los jueces conozcan de los casos realmente graves y que no pueden ser solucionados alternativamente.

50 Samuel González et al., El sistema de justicia penal y su reforma, México, Fontamara, 2005, p. 60. 
2. El Ministerio Público no tendrá poder de autoridad en la investigación. Durante todo el procedimiento penal se encontrará en igualdad de circunstancias con el imputado, el defensor, la víctima y la asesoría jurídica.

3. Todas las fases del procedimiento penal deberán ser vigiladas y controladas por la autoridad jurisdiccional. Toda afectación a derechos fundamentales del imputado, la víctima y demás involucrados en el hecho punible o el procedimiento, deberán ser autorizadas o validadas por el Juez.

4. Los Jueces que intervengan en las fases de investigación, preparación, juicio y ejecución, serán distintos, para efectos de conservar su imparcialidad y objetividad.

5. Las pruebas, para ser valoradas y tomadas en cuenta en el procedimiento, deberán ser obtenidas sin violación a los derechos humanos y fundamentales, respetando la audiencia y la contradicción de todos los sujetos procesales, y deberán ser reproducidas ante el Juez en el procedimiento. Ningún Juez tendrá la facultad de allegarse pruebas o perfeccionar las ofrecidas, admitidas y desahogadas, siempre conservando su imparcialidad y objetividad.

6. La presunción de inocencia y la presunción victimal serán pilares esenciales del Sistema de Justicia Penal, por lo que sólo se admitirá la prisión preventiva en casos excepcionales, y deberán buscarse medidas de protección y cautelares a favor de la víctima, en forma inmediata y adecuada para proteger sus derechos durante el procedimiento.

7. Los sujetos involucrados en la investigación, comprobación, juzgamiento del delito y ejecución de la sentencia, tendrán el derecho de impugnar las determinaciones de autoridad que les afecten. 
8. Defensa y Asesoría Jurídica serán derechos verdaderos e irrenunciables del imputado, la víctima, ofendidos y demás involucrados en el procedimiento.

Vi. Víctimas $y$ sus derechos en el Sistema Penal Acusatorio

La víctima es la persona que directamente es afectada o puesta en peligro en sus bienes jurídicos por la realización del hecho delictivo (titular del bien jurídico). Los ofendidos son aquellos relacionados con la víctima por cuestión familiar o de parentesco, como cónyuges, concubinos, conviviente, parientes por consanguinidad en la línea recta ascendente o descendente sin limitación de grado, por afinidad y civil, o cualquier otra persona que tenga relación afectiva con la víctima, o fueran dependientes económicos del titular del bien jurídico. Todos podrán intervenir en el procedimiento en auxilio de los investigadores y acusadores, aportando datos de prueba, realizando investigaciones, y proponiendo las bases de la acción civil de reparación del daño.

Para ejercer sus derechos, la víctima debe tener acceso a la justicia. La garantía de Acceso al Justicia, implica la posibilidad de que los seres humanos acudan a la administración de justicia, a un órgano jurisdiccional, para solicitar su actuación y, en consecuencia, el órgano jurisdiccional reciba cualquier petición y la responda conforme a derecho, según los artículos 13, 14 y 17 de la Constitución Federal Mexicana, 8 de la Convención Americana sobre Derechos Humanos y 14 del Pacto Internacional de Derechos Civiles y Políticos.

Es decir, implica la solicitud de protección, de declaración o de garantía de la efectividad de un derecho, pues la función esencial de los Tribunales es la de garantizar el ejercicio adecuado de los derechos fundamentales, admitiendo las peticiones para que el derecho sea vea satisfecho en la mayor medida posible; tales peticiones se 
tramiten conforme a los normas previamente establecidas, en caso de que se pretenda afectar derechos, e incluso creando los procedimientos para el supuesto de garantizarlos; siendo el trato imparcial o ajeno a los intereses del acusador, la víctima, el imputado y el defensor; independiente o ajeno a los intereses del sistema político; y siendo las personas tratadas en un plano de igualdad real, tomando en cuenta sus desigualdades, su cultura, sus creencias, su forma de pensar y cómo eso influyó en el hecho.

Este Acceso a la Justicia, existe porque la víctima es un sujeto de derechos, no un objeto del proceso (al igual que el imputado), y, en consecuencia, no se encuentra a la sombra del Fiscal que representa al Estado, sino que está a la par de éste y de quien es acusado por la comisión del hecho punible, con la finalidad de hacer valer sus intereses y sea escuchado en el procedimiento en el cual se resuelva sobre las consecuencias jurídicas del evento.

Por lo anterior la víctima, al tener la posibilidad de dirigirse ante los tribunales a exigir justicia y protección a sus derechos, cuenta con algunas facultades y atribuciones que deben observarse en este nuevo esquema procesal penal acusatorio, como lo son:

\section{Formas de intervención en el procedimiento penal}

La víctima podrá investigar y aportar datos de prueba, como auxiliar del Fiscal (coadyuvante en estricto sentido), como acusador civil (coadyuvante de acusación) o como acusador particular.

Como este sistema busca la igualdad de partes, la víctima y el ofendido deben contar con una asesoría jurídica de calidad (artículo 20 apartado C, Constitucional), por lo que en cualquier etapa del procedimiento los orientará en su participación, les representará e intervendrá en la protección, cumplimiento y observancia del ejercicio efectivo de sus derechos. Esta asesoría de calidad la llevará a cabo un licenciado en derecho especializado en sistema penal acusatorio, y en caso de que la víctima u ofendido no tengan medios 
económicos para designarlo, el Estado estará obligado a proporcionarle un asesor que le auxilie en el procedimiento.

Con base a lo anterior, la víctima u ofendido podrá actuar de tres diversas maneras en el procedimiento penal: una como coadyuvante del Fiscal en estricto sentido, dentro de la etapa de investigación, aportándole datos de prueba que sean necesarios para robustecer el caso y decida sobre el ejercicio de la acción o la formulación de la acusación; la segunda como acusador civil o coadyuvante de acusación, en la etapa de preparación, donde se hará cargo de la búsqueda, acusación y presentación de las pruebas respecto de la condena a la reparación del daño, con el fin de que el Fiscal sólo se distraiga en la investigación del hecho delictivo y en la justificación de las sanciones de Estado; y por último como acusador particular, desde la etapa de investigación, donde el Fiscal no tendrá participación, ya que la víctima u ofendido realizará la investigación, acusación y producción de pruebas directamente ante los jueces, para demostrar tanto el delito, la responsabilidad del acusado, y la reparación del daño que deba cubrirse.

Esto implica que en los dos primeros casos (coadyuvancia en estricto sentido y coadyuvancia de acusación -acusación civil-), la acción penal será pública y estará a cargo del Fiscal, mientras que en último supuesto (acusador particular) la acción penal será particular y estará a cargo de la víctima u ofendido que así lo decida, quien presentará directamente la querella ante el Juez de Control, en aquellos hechos punibles de querella, que tengan pena alternativa, o cuya punibilidad máxima no exceda de tres años de prisión.

La acción penal particular se limita por el Código Nacional de Procedimientos Penales, a aquellos casos en que para la investigación se necesite la ejecución de actos de molestia (con o sin control previo del juez), pues en esos supuestos, el Ministerio Público deberá continuar con la investigación y decidirá sobre el ejercicio de la acción penal. Esto puede hacer nugatorio el derecho constitucional de Acceso a la justicia, a través de la acusación particular, y provo- 
car el desistimiento de la víctima u ofendido de optar por esta vía. Sería conveniente replantearse tal restricción, y sólo indicar que debe acudirse a la Fiscalía o juez de control, para pedir su solicitud, autorización y ejecución, según sea el caso, en aquellos actos de molestia que deban ejecutarse para la investigación del hecho punible, y continuar la víctima u ofendido con la acción dentro del procedimiento, pues finalmente las restricciones a la libertad no están permitidas en esta vía, y los demás derechos pueden ser controlados por el Juez, como ocurre en instancias no penales.

2. Salidas alternas para la solución del conflicto penal

Como hemos dicho, en un Estado Constitucional de Derecho, un Sistema Penal que tiene como base los derechos humanos, será aquel que busque su protección, tratando de afectarlos en forma mínima.

El nuevo sistema penal obliga a la autoridad a implementar medidas alternativas que no impliquen necesariamente un procedimiento judicial para la imposición de una sanción. Estas medidas buscarán que se logre la reparación del daño, que el imputado tome conciencia de su acción, se reintegre a la sociedad, no se contamine en reclusión, y se depuren las acciones procesales, para que los jueces conozcan de los casos realmente graves que no puedan ser solucionados alternativamente.

El principio de intervención mínima busca que las autoridades generen acciones para lograr una reacción penal más justa y protectora de derechos humanos. En consecuencia, la actuación del Sistema Penal no debe ser expansiva, ni que genere poca Política Criminal dura, sino más soluciones alternativas y menos lesivas, lo más participativas posibles, hasta llegar a poder aplicar otro tipo de políticas, no necesariamente criminales. ${ }^{51}$

51 Alberto Binder, Política criminal, de la formulación a la praxis, Argentina, Ad Hoc, 1997, pp. 38 y 39. 
Surgen así los mecanismos alternativos de solución de controversias, con la finalidad de implementar un procedimiento menos costoso, más conveniente y participativo, comparándolo con el proceso judicial, en el afán de resolver los conflictos, en forma más rápida, permitiendo mantener el control sobre el resultado no arriesgándose a una decisión "todo-nada" que implica una resolución judicial. ${ }^{52}$ El actual discurso sobre la víctima intenta dar nuevas dimensiones a la política criminal. Trata de lograr una justicia reparadora hacía y de la víctima, y respecto del imputado, trata de ofrecer la posibilidad de que tome pleno contacto e individualice el daño que ha causado y sus consecuencias en la vida de la víctima. ${ }^{53}$

La negociación, conciliación y mediación, como salidas alternas de solución del conflicto, se reflejan principalmente en los acuerdos reparatorios y suspensión condicional del proceso (suspensión del proceso a prueba), que en ambos casos se atiende el interés de la víctima a su reparación integral, como el interés del imputado de mantener su libertad, tomando conciencia de su hecho, e implementar mecanismos de reinserción que le ayuden a llevar una vida sin delito.

Los acuerdos reparatorios consisten en un acuerdo entre víctima e imputado, prestado en forma libre y con pleno conocimiento de sus derechos, mediante el cual el imputado se compromete a reparar a la víctima de una forma que resulte satisfactoria para ésta, produciendo la extinción de la responsabilidad penal una vez que el acuerdo se encuentra cumplido. Esta reparación puede ser material o simbólica y puede consistir, incluso, en una disculpa. Proceden respecto de ciertos y determinados hechos punibles, como aquellos que afectan bienes jurídicos disponibles (querella), patrimoniales no violentos y culposos, pero impidiéndose en delitos de violencia

52 Manual de Mediación. Corte Suprema de Justicia, Oficina de Mediación, Paraguay, 2005, p. 4.

53 Elías Neuman, La mediación penal y la justicia restaurativa, México, Porrúa, 2005, p. 44. 
familiar, por la protección de las víctimas vulnerables. La oportunidad para celebrarlos se da a partir desde la investigación y hasta antes del dictado del auto de apertura a juicio (aunque debería ser posible que se pudieran realizar durante todo el proceso, con base al principio de efectividad e intervención mínima).

La suspensión condicional del proceso (o suspensión del proceso a prueba), puede definirse como una negociación para suspender la investigación y el proceso por un tiempo determinado, a cambio de que el imputado acepte cumplir ciertas obligaciones o condiciones (plan de reinserción adelantado) que son aprobadas en audiencia por el Juez de Control, y un plan de reparación integral a favor de la víctima. Procede en hecho punibles cuya media aritmética no exceda de cinco años de prisión, una vez que se haya vinculado a proceso al imputado, y hasta antes del dictado del auto de apertura de juicio.

Tanto en acuerdos reparatorios, como en suspensión condicional del proceso, si el imputado cumple las condiciones establecidas, y no es objeto de una nueva formalización de imputación por hechos distintos, se extingue la acción penal por los ilícitos que motivaron la investigación, y no existirán antecedentes penales. Además, toda la información que se vierta en las negociaciones, en caso de que no se cumplan o no se lleguen a las salidas alternas, no podrá emplearse en el proceso, ${ }^{54}$ pues de lo contrario ninguna víctima o imputado se animarían a emitir información o reconocer determinadas situaciones, si supieran que esa información pudiera luego utilizarse en su perjuicio.

Estos mecanismos empoderan nuevamente a las víctimas, pues son quienes podrán llevar a cabo las negociaciones a favor de sus derechos, y con lo cual el imputado podrá también salir beneficia-

54 Alejandra Díaz Gude, "La experiencia de la mediación penal en Chile", en Política Criminal. Revista Electrónica Semestral de Políticas Públicas en Materias Penales. Vol. 5, N. 9, Julio 2010, Colombia. Disponible en: <http://www.politicacriminal. cl/Vol_05/n_09/Vol5N9A1.pdf>. 
do, al no ser privado de su libertad ni restringido con otro tipo de sanciones, logrando adelantar y cubrir con la reparación del daño integral, y realizando las actividades necesarias para disminuir los efectos lesivos del hecho punible realizado.

\section{Contradicción, Rectificación y otros derechos}

También la víctima u ofendido cuentan con el derecho a la contradicción, que no es simplemente la garantía de defensa del imputado. El principio de contradicción esencialmente se traduce en la posibilidad de debatir y controvertir.

Por lo anterior, como regla general, las decisiones que puedan afectar derechos fundamentales, deben realizarse en audiencia pública, previa petición de parte, y dando la oportunidad al posible afectado (imputado, víctima o tercero) de argumentar en contra de la petición. Es decir, la autorización para afectar derechos fundamentales debe ser previa y tomada en audiencia contradictoria.

Ahora bien, como regla de excepción, en determinadas decisiones que por su naturaleza no sea conveniente su comunicación por la necesidad urgente o cautela constitucional, podrá autorizarse afectación de derechos fundamentales sin otorgar el derecho a contradicción previa, pero siempre deberá garantizarse su debate posterior.

Relacionada con la contradicción y el Acceso a la Justicia, se encuentra el principio de rectificación, que implica la posibilidad de que los sujetos involucrados en el procedimiento penal, puedan impugnar las decisiones que les perjudiquen. Así, pone a su disposición un medio por el cual el afectado por un acto de autoridad, podrá acudir a la jurisdicción para que restablezca sus derechos. En caso de que se compruebe error en la decisión, da lugar a una reparación por parte del Estado (indemnización que no sólo será la prevista en el artículo 113 Constitucional por motivo de actividad administrativa irregular del Estado, sino por actos u omisiones ilegales de cualquier autoridad que violenten derechos humanos, 
conforme al nuevo párrafo tercero del artículo $1^{\circ}$ de la misma Carta Magna, como se desprende de la reforma de 10 de junio de 2011). Esto provocará mayor capacitación de las autoridades y sujetos procesales, pues en caso de error comprobado y pago de indemnización, el Estado podrá repetir y requerir el pago a quien haya provocado el error.

Además, la víctima u ofendido, así como toda persona, deberá ser tratada como ser humano sujeto de derechos, y no como objeto del procedimiento, respetando su dignidad, seguridad e integridad física, psíquica y moral.

Así, el Fiscal y los Jueces deben tomar en cuenta las condiciones particulares de las personas y del caso, y no podrán actuar con criterios de discriminación motivada por origen étnico o nacional, género, edad, discapacidades, condición social, condiciones de salud, religión, opiniones, preferencias, estado civil o cualquier otra que atente contra la dignidad humana y tenga por objeto anular o menoscabar los derechos y libertades de las personas.

En consecuencia, debe respetarse la intimidad de cualquier persona que intervenga en el procedimiento, sobre todo la vida privada, datos personales, libertad de conciencia, el domicilio, la correspondencia, los papeles y otros objetos privados, así como las comunicaciones privadas. Es por ello que se prohíbe el empleo de tratos crueles, inhumanos o degradantes; la tortura, la discriminación, la exhibición de las personas como culpable o víctima (para evitar los diversos tipos de revictimización), y todo aquello que atente contra los derechos humanos y fundamentales de las personas.

Y finalmente, el derecho a la interpretación Pro homine, también llamado "Pro persona", principio creado con fundamento en la dignidad humana, que implica que en caso de que disposiciones normativas aplicables sean contradictorias, o que de su interpretación o de una norma deriven diversos significados, deberá escogerse aquel que beneficie más a la protección y garantía de los derechos fundamentales. 
Así, en el supuesto de que se encuentren enfrentados derechos de diversas personas, deberá observarse, además, las reglas de adecuación, necesidad y proporcionalidad para equilibrar los derechos en la medida de lo posible.

Finalmente, como este sistema busca la igualdad de partes, la víctima y el ofendido deben contar con una asesoría jurídica de calidad (artículo 20 apartado C, Constitucional), por lo que en cualquier etapa del procedimiento podrán designarla para orientación, representación e intervención en la protección, cumplimiento y ejercicio de sus derechos. Esta asesoría de calidad la llevará a cabo un licenciado en derecho especializado en sistema penal acusatorio, dependiente de los Consejos Generales o Estatales de víctimas, para no coincidir con los órganos de defensoría, y lograr una verdadera imparcialidad; y en caso de que la víctima u ofendido no tengan medios económicos para designarlo, el Estado estará obligado a proporcionarle un asesor que le auxilie en el procedimiento.

Este asesor jurídico tendrá la obligación de hacer efectivos los derechos de la víctima; informarla sobre el proceso y sus derechos, manteniendo constante comunicación; asesorarla, representarla y asistirla en los actos procedimentales; auxiliarle en las actividades de negociación para lograr salidas alternas; vigilar las actividades del Fiscal, y auxiliarlo en la investigación (coadyuvancia); ofrecer medios de prueba, por lo que podrá contar con investigadores privados; apoyar y representar a la víctima en la acusación civil (coadyuvancia de acusación), o en la acusación particular.

\section{Presunción victimal}

Estamos acostumbrados a escuchar sobre la presunción de inocencia, pero no respecto de la presunción victimal. La presunción de inocencia es la garantía del imputado de recibir el trato de no autor o partícipe de un hecho delictivo, hasta en tanto no se demuestre su culpabilidad; es decir, ninguna persona puede ser tratada como 
culpable hasta que esto no se declare en sentencia definitiva. Por lo anterior, como regla de tratamiento del imputado restringe al máximo la limitación de la libertad personal, y como regla de juicio, impone la carga acusatoria de la prueba al Estado, hasta la absolución en caso de duda.

Pero, si bien pareciera que todos los dados están cargados a favor del imputado, frente a la presunción de inocencia existe la presunción victimal, que prevalece y se pondera en la mayoría de los supuestos procesales de enfrentamiento de derechos.

Le llamo presunción victimal al derecho de tratamiento como víctima u ofendido a todo afectado de un hecho antisocial, para efecto de realizar ciertos actos inmediatos y urgentes para su protección y restablecimiento de sus derechos, sin necesidad de que exista una sentencia firme que la califique como víctima u ofendido. Se basa en la apariencia del buen derecho, por lo que no se requiere prueba plena o declaración firme de la existencia del hecho delictivo y de la culpabilidad del responsable, sino que basta la sola probabilidad del hecho o del posible daño, para reaccionar preventivamente a su favor. Esta presunción victimal no opera en todo momento, pues frente a ella existe la presunción de inocencia del imputado, por lo que los derechos enfrentados deben ser equilibrados o en su caso ponderados con base a los principios del sistema penal acusatorio, entre ellos el debido proceso y pro homine.

Así, algunos derechos basados y ponderados desde una perspectiva de presunción victimal, son los siguientes:

1. No ser discriminado ni tratado en forma inhumana o degradante;

2. Que se proteja y resguarde su integridad física o psicológica;

3. Recibir, en áreas o instituciones especializadas, atención médica, psicológica y protección especial de su integridad física y psíquica de urgencia, o cuando lo solicite o requiera; 
4. Contar con asesoría jurídica gratuita en forma inmediata, desde que se realice el hecho flagrante, o se interponga la denuncia o querella;

5. Solicitar medidas cautelares y providencias necesarias para la protección y restitución de sus derechos, con el fin de lograr el restablecimiento de las cosas al estado que tenían antes del hecho, siempre que haya suficientes elementos para decidirlo, y sin necesidad de que exista una sentencia condenatoria firme;

6. Que se le garantice el daño causado en forma real, integral y ágil;

7. Que se resguarde su identidad y demás datos personales cuando sean menores de edad, se trate de delitos de violación, contra la libertad y el normal desarrollo psicosexual, violencia familiar, secuestro, trata de personas, o cuando a juicio del juzgador sea necesario para su protección, salvaguardando en todo caso los derechos de la defensa; y

8. No ser objeto de información ni presentado ante los medios de comunicación o ante la sociedad sin su consentimiento, para evitar su re-victimización, la contaminación del juzgador y efectos corruptores en el proceso.

Basado en lo anterior, la presunción victimal la observamos en los ejercicios de ponderación de derechos en causas de justificación, donde los "autores" están autorizados a lesionar bienes jurídicos en defensa legítima, estado de necesidad o cumplimiento de un deber; también en detenciones en flagrancia y revisiones personales para evitar que el hecho delictivo siga produciendo sus efectos sobre las víctimas; las medidas de protección, precautorias y cautelares para disminuir los riesgos de afectación a las víctimas, basadas en la sola probabilidad de ese daño, y sin necesidad de prueba plena que lo evidencie; la protección de su imagen y datos personales, para evitar riesgos de re-victimización, y la base de probabilidad para las 
determinaciones tomadas por los jueces en audiencia preliminares al juicio, donde la duda no favorece al imputado, sino a la víctima para protegerle.

Si bien el sistema de justicia penal busca el respeto a los derechos de los involucrados, en este modelo acusatorio mexicano la presunción victimal busca que durante el procedimiento prevalezca una mayor protección a la víctima u ofendió, al ser sujeto de derechos, y no un objeto del proceso, pero afectando lo menos posible al imputado.

\section{vit. Conclusiones}

El sistema jurídico tiene una finalidad, no sólo se reduce a la formulación y existencia de leyes a las cuales el individuo deba sujetar su actuar, sin importar que resuelva o no un problema; el derecho, es más que pura legislación; contiene un valor que es la justicia, y la cual se alcanza cuando la aplicación de la norma es eficaz, pues resuelve, o por lo menos aminora, el problema social para la cual fue creada. Así, la sociedad no es la que debe adecuarse a la norma, sino que ésta, como producto cultural, es la que debe ajustarse a los individuos y provocar su mejor desarrollo al alcanzar la justicia.

Bajo esa tesitura, el Sistema de Justicia Penal formaliza el control social a través de la protección de los derechos humanos de todos los involucrados; es decir, la formalización implica transparencia y claridad del sistema, así como la existencia de principios valorativos que deben observarse en su aplicación. ${ }^{55}$ En virtud de que existen varios sistemas o mecanismos que pretenden reaccionar contra las desviaciones sociales, y algunos se insertan en la estructura del Estado, consecuentemente, será la forma o clase de Estado la que

55 Winfried Hassemer, Persona, mundo y responsabilidad. Bases para una teoría de la imputación en derecho penal, s. cd., Temis, 1999, p.8. 
condicione las prácticas de la Política Criminal; ${ }^{56}$ y en un Estado Constitucional de Derecho, esos mecanismos se ven sustentados en la protección de los Derechos Fundamentales de las personas a las que va dirigido, al someterse a normas de actuación diseñadas para asegurar la objetividad de la intervención y el respeto de los individuos involucrados en el conflicto. ${ }^{57}$

Una verdadera Política Criminal democrática, que tenga como límites los Derechos Humanos y Fundamentales de las personas, será aquella que construya un mecanismo de control social penal que tienda a la protección de los seres humanos, afectándolos lo menos posible.

En este nuevo sistema, y en virtud de que el sistema penal inquisitivo sólo crea mayor violencia y desigualdad, surge el Principio de Efectividad, que tiene la finalidad de resolver eficazmente el conflicto de intereses que se genera por el delito, y no necesariamente en sentencia de condena; lo cual beneficia a la víctima del delito, pues la empodera de derechos que había perdido, al haber sido considerada un simple medio de prueba más, pero no un sujeto procesal. En este nuevo esquema, además de existir medios alternos de solución del conflicto, para lograr una reparación integral más rápida y adecuada a la víctima u ofendido del hecho delictivo, también se le otorgan mayores herramientas de participación, de asesoramiento, y de control de actuación de la autoridad, para lograr un verdadero Acceso a la Justicia.

El nuevo modelo acusatorio mexicano toma en cuenta a la víctima que había sido olvidada en el sistema penal, pues ya no sólo se trata de un objeto del proceso, o quien sufre el daño, sino que cuenta con una serie de facultades y garantías de protección, relacionadas principalmente con solucionar eficaz y rápidamente el conflicto penal, atendiéndola de inmediato, y generando una pro-

56 Roberto Bergalli, "La instancia judicial", en El pensamiento criminológico, Vol. II Estado y Control, s. cd., Temis, 1983, p. 73.

57 Antonio García-Pablos de Molina, Tratado..., op. cit., pp. 197 y 198. 
tección de las autoridades investigadores y tribunales para favorecer en su reparación del daño integral. Así, la protección a la víctima es mayor, pues deja de ser un mero objeto para la investigación, y se convierte en un sujeto procesal que auxiliará en ella, y buscará que se le repare el daño en forma integral; por ello el incremento de medidas alternativas de solución del conflicto que se crean para favorecerla.

Por lo anterior, la víctima cuenta con el derecho a informarse en forma completa, y en todo momento, de la situación del procedimiento; se incrementan las medidas cautelares de protección y aseguramiento de sus derechos; cuenta con una intervención activa para investigar y entregar pruebas al acusador, y proponer la acción civil de reparación del daño; puede impugnar todo lo que estime le perjudica, como actuaciones del Ministerio Público y los Jueces; y en algunos casos se le permite realizar la investigación penal por sí misma, ejercitar la acción y sostener la acusación ante el Juez.

En síntesis, el nuevo procedimiento penal acusatorio es una búsqueda de seguridad jurídica de la persona, al saber que en caso de que se cometa un hecho que pueda ser calificado de punible, el Estado observará todos y cada uno de los requisitos y elementos previos, tendientes a lograr el mínimo malestar posible, y el mayor beneficio posible de los involucrados, evitando la privación de la libertad a toda costa, a cambio de una resolución integral y efectiva del conflicto a favor de los afectados. Es decir, establecer un camino razonable y humano para el tratamiento del delito, sin buscar necesariamente el privar de la libertad a las personas, sino tratar de solucionar el conflicto de intereses entre los involucrados: víctima, su interés en su protección y reparación del daño en forma integral y efectiva, imputado, su interés en no ser restringido gravemente de sus derechos, y acceder a posibilidades de reparar el daño en forma adecuada y menos lesiva,

Este nuevo sistema implica un nuevo tipo de civilización, un nuevo tipo de cultura, dejar atrás un chip de siglos de una visión au- 
toritaria en el tratamiento de las conductas desviadas, e incluir un nuevo programa mental, social e institucional de visión humana y efectiva. Lo más importante es modificar estereotipos o paradigmas no protectores de derechos humanos, cambiar la cultura jurídica inquisitiva y sustituirla por una cultura jurídica garantista, lo que nos corresponde a todos los integrantes de este colectivo social: observar a la víctima olvidada, y recordar que tiene derecho a tener derechos: a ser humano, y no objeto del sistema penal.

\section{Vili. Fuentes de investigación}

Bachmaier, Lorena, Proceso penal y sistemas acusatorios, Madrid, Marcial Pons, 2008.

Bergalli, Roberto. "La instancia judicial", en El pensamiento criminológico. Vol. II Estado y Control. Colombia, Temis, 1983.

Binder, Alberto. Política criminal, de la formulación a la praxis. Buenos Aires, Ad Hoc, 1997.

Bustos, Juan. Lecciones de Derecho Penal, Madrid, Trotta, 1997.

Cátedra de Sociología Jurídica, impartida por el Mtro. Jesús Antonio de la Torre Rangel, en la Maestría en Derecho de la Universidad Autónoma de Aguascalientes; 28 de marzo y 12 de abril de 2003.

Correas, Oscar. Introducción a la sociología jurídica. México, Distribuciones Fontamara, 2000.

De la Torre Rangel, Jesús Antonio. Iusnaturalismo, Personalismo y Filosofía de la Liberación. Una visión integradora. Sevilla, Mad, 2005.

- - Jesús Antonio. Sociología jurídica y uso alternativo del derecho. Aguascalientes, ICA, 1997.

Díaz Gude, Alejandra. "La experiencia de la mediación penal en Chile”. Política Criminal. Revista Electrónica Semestral de Políticas Públicas en Materias Penales. Vol. 5, N. 9, Julio 2010. Colombia. http://www. politicacriminal.cl/Vol_05/n_09/Vol5N9A1.pdf

Donnelly, Jack. Derechos humanos universales. México, Gernika, 1998. 
Ferrajoli, Luigi. Derecho y razón; teoría del garantismo penal. Madrid, Trotta, 2011.

—-Derechos y garantías; la ley del más débil. Madrid, Trotta, Madrid, 1999.

García Manrique, Ricardo y Escobar Roca, Guillermo. "Estado de Derecho", cátedra dentro del curso Estado de Derecho y Derechos Humanos, dentro del Programa de Apoyo a Defensores de Derechos Humanos en Iberoamérica, de la Federación Iberoamericana del Ombudsman, Alcalá de Henares, Madrid, 2007.

García-Pablos de Molina, Antonio. Tratado de criminología. Valencia, Tirant lo blanch, 2003.

GonzÁlez, Samuel et al., El sistema de justicia penal y su reforma, México, Fontamara, 2005.

Gössel, Karl, El proceso penal ante el Estado de Derecho, Perú, Editora Jurídica Grijley, 2004.

Gramsci, Antonio, Cuadernos de la Cárcel, México, Era, 1999.

Grijelmo, Alex La seducción de las palabras; un recorrido por las manipulaciones del pensamiento. Madrid, Santillana Ediciones Generales, 2004.

Hassemer, Winfried. Persona, mundo y responsabilidad. Bases para una teoría de la imputación en derecho penal. Colombia, Temis, 1999.

LaClau, Martín. Conducta, norma y valor; ideas para una nueva comprensión del derecho. Buenos Aires, Abeledo Perrot, 1999.

Manual de Mediación. Corte Suprema de Justicia, Oficina de Mediación. Paraguay, 2005.

Mir Puig, Santiago, Nuevas tendencias en politica criminal -Una auditoría al Código Penal español de 1995-, Buenos Aires, B de F, 2006.

Muñoz Conde, Francisco, Búsqueda de la verdad en el proceso penal, Buenos Aires, Hammurabi, 2000.

Neuman, Elías. La mediación penal y la justicia restaurativa. México, Porrúa, 2005.

Ortiz, Serafín, Los fines de la pena, México, Instituto de Capacitación de la PGR, 1993. 
Pastrana, Juan, Implementación del proceso penal acusatorio adversarial en Latinoamérica, México, Flores Editor y Distribuidor, 2009.

Roxin, Claus, La evolución de la política criminal, el derecho penal y el proceso penal, España, Tirant lo Blanch, 2000.

Saurre, Oscar Emilio, La crisis de legitimidad del sistema jurídico penal, Buenos Aires, Editorial Universidad, 1998.

Tribunal Constitucional Español, sentencia 53/1985, del 11 de abril de 1985. 